\title{
Research Article \\ Effects of CNT Diameter on the Uniaxial Stress-Strain Behavior of CNT/Epoxy Composites
}

\author{
N. Yu and Y. W. Chang \\ Department of Mechanical Engineering, College of Engineering, Yuan Ze University, \\ Taiwan135 Yuan-Tung Road, Chungli 32003, Taiwan \\ Correspondence should be addressed to N. Yu, nyu@saturn.yzu.edu.tw
}

Received 21 February 2008; Revised 15 June 2008; Accepted 6 August 2008

Recommended by Ching Ping Wong

The present work studies the effects of the diameter of carbon nanotube (CNT) as well as CNT weight fraction on the uniaxial stress-strain behavior, stiffness, and strength of CNT-reinforced epoxy-matrix composites. The experimental results show that average Young's moduli of $5 \mathrm{wt} \%$-CNT/epoxy composites with a CNT diameter $D<20 \mathrm{~nm}$ and $D=40 \sim 60 \mathrm{~nm}$ are $4.56 \mathrm{GPa}$ and $4.36 \mathrm{GPa}$, and the average tensile strengths are $52.89 \mathrm{MPa}$ and $46.80 \mathrm{MPa}$, respectively, which corresponds to a percentage increase of $61.1 \%, 54.1 \%, 106 \%$, and $82.3 \%$, respectively. Two micromechanics models are employed and the predicted Young's moduli are benchmarked with the experimental data of MWCNT-reinforced epoxy-matrix composites.

Copyright (c) 2008 N. Yu and Y. W. Chang. This is an open access article distributed under the Creative Commons Attribution License, which permits unrestricted use, distribution, and reproduction in any medium, provided the original work is properly cited.

\section{INTRODUCTION}

In view of its excellent stiffness and strength, the carbon nanotube $(\mathrm{CNT})$ is considered as an ideal candidate for the reinforcement in composites. Andrews et al. [1] added $5 \mathrm{wt} \%$ single-walled carbon nanotubes (SWCNTs) in isotropic petroleum pitch. The elastic modulus of SWCNT/petroleum increased from $34 \mathrm{GPa}$ to $78 \mathrm{GPa}$, whereas the tensile strength increased from $490 \mathrm{MPa}$ to $850 \mathrm{MPa}$. Jia et al. [2] used AIBN, a free radical initiator, and Gong et al. [3] used the surfactant dodecylether $\left(\mathrm{C}_{12} E_{8}\right)$ as a processing aid to improve the interfacial bonding between multiwalled carbon nanotubes (MWCNTs) and the matrix. The tensile test results of Allaoui et al. [4] reported that Young's modulus and the yield strength were doubled and quadrupled for MWCNT/epoxy composites with 1 and $4 \mathrm{wt} \% \mathrm{CNTs}$, respectively, in comparison with those of pure epoxy samples. However, the threepoint bending test results by Lau et al. [5] indicated that the flexural strengths of all CNT composites were relatively lower than the pure epoxy sample. The nanoindentation results by $\mathrm{Li}$ et al. [6] using an atomic force microscope showed an increase in elastic modulus by $75 \%$ and hardness by $30 \%$ in the epoxy reinforced by $5 \mathrm{wt} \%$ SWCNTs in comparison with those of neat epoxy. Song and Youn [7] reported that the tensile strength of epoxy filled with well-dispersed CNTs increased as the CNT weight fraction increased, yet that of the composite filled with poorly-dispersed CNTs decreased. Thostenson and Chou [8] used a microscale twin-screw extruder to align MWCNTs in polystyrene composite films. The interface between CNT and matrix was studied by Schadler et al. [9], Ajayan et al. [10], and Cooper et al. [11]. CNTs were also used as reinforcements in ceramic- or metalmatrix composites [12-15].

In the present work, MWCNTs with a variety of weight fractions and diameters are added into epoxy and the composites are subjected to uniaxial tensions. The mechanical properties of composites containing CNTs at the same weight fraction, yet different CNT diameters, are compared and, therefore, the effects of CNT diameter on Young's modulus and tensile strength of MWCNT/epoxy composites are characterized.

\section{EXPERIMENTS}

As received MWCNTs purchased from Desunnano Co. in specific weight fraction $(1 \mathrm{wt} \%, 2 \mathrm{wt} \%, 3 \mathrm{wt} \%, 4 \mathrm{wt} \%$, and $5 \mathrm{wt} \%$ ) are mixed with $7.5 \mathrm{~mL}$ epoxy resin E-120 together with $2.5 \mathrm{~mL}$ associated hardener $\mathrm{H}-100$. It is noted that the 


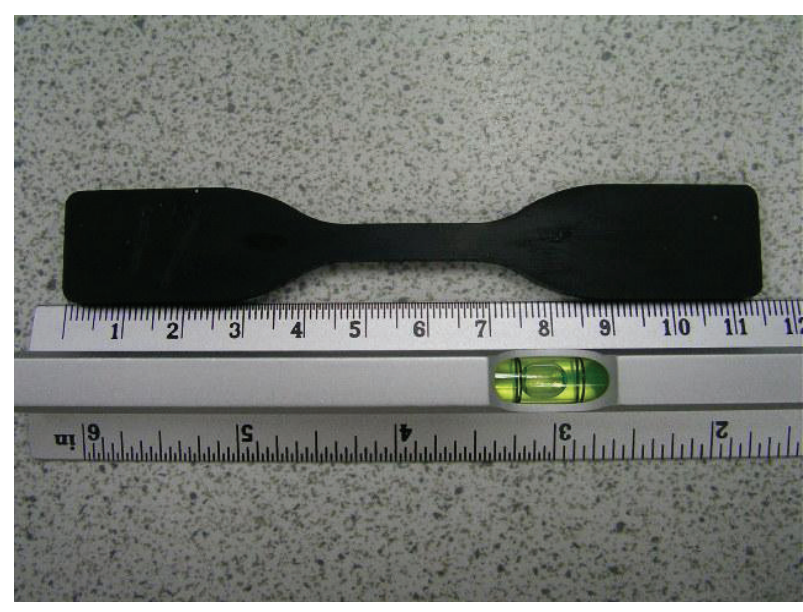

FIGURE 1: MWCNT/epoxy specimen.

resin-to-hardener volume ratio is kept at $3: 1$. The mixture is first sonicated for 10 minutes and then stirred amply for 5 minutes. The sonication-stirring step is repeated three times in order to ensure the uniform distribution and the separation of the entangled MWCNTs. The nanotube/epoxy mixtures are then poured into an aluminum mold, vacuumed in an oven for 30 minutes, and then released to the atmosphere for 10 minutes. This step is repeated two times in order to remove air bubbles from the mixtures. The mixture is then cured in atmosphere. After simple machining, the specimen is ready for test; see Figure 1. The dimensions of the specimen follow ASTM D638 Type IV. In the present work, there are pure epoxy and composites with $1 \mathrm{wt} \%-, 2 \mathrm{wt} \%-$, $3 \mathrm{wt} \%-, 4 \mathrm{wt} \%-$, and $5 \mathrm{wt} \%-\mathrm{MWCNT}$ with their diameters being less then $20 \mathrm{~nm}$ or between 40 to $60 \mathrm{~nm}$. The weight fraction $W_{t} \%$ of CNTs is given by

$$
W_{t} \%=\frac{W_{\mathrm{CNT}}}{W_{\mathrm{CNT}}+W_{e}+W_{h}} \times 100 \%,
$$

where $W_{\mathrm{CNT}}, W_{e}$, and $W_{h}$ are the weight of the carbon nanotubes, epoxy resin, and hardener in grams, respectively. Three specimens for each of the group-neat epoxy, $1 \mathrm{wt} \%$-, $3 \mathrm{wt} \%-$, and $5 \mathrm{wt} \%-\mathrm{MWCNT/epoxy}$, and only one specimen for the group $2 \mathrm{wt} \%$ - and $4 \mathrm{wt} \%-\mathrm{MWCNT} / \mathrm{epoxy}$ is prepared. The total number of samples is twenty five. If the dispersion of MWCNTs is uniform in the epoxy resin, the composite specimen can be regarded as isotropic. The testing of the composites follows the ASTM D638 standard tensile test. The grip of the microcomputer tensile tester (Model No. H-10KS, Hounsfield Test Equipment Co.) can be controlled in such a manner that the relative displacement rate of the grips is $1.0 \mathrm{~mm} / \mathrm{min}$ so that the test can be regarded as quasistatic.

At the time of measurement, a resistance-type (120 ohms) strain gage is pasted on the surface of the specimen in the axial direction. The elastic modulus of MWCNT/epoxy composite is determined by calculating the slope of the linear portion of the stress-strain curve.

\section{THE MODELS}

In the present work, two micromechanics models, Eshelby [16] and Mori-Tanaka [17], are employed to predict Young's modulus of epoxy reinforced by randomly distributed MWCNTs. The former ignores the interaction between CNTs and gives the effective elastic constants $[\bar{C}]$ of the composite as follows:

$$
[\bar{C}]=\left[C^{M}\right]+V_{I}\left(\left[C^{I}\right]-\left[C^{M}\right]\right)[X],
$$

where $\left[C^{M}\right]$ is the stiffness matrix of the matrix, $\left[C^{I}\right]$ is the stiffness matrix of CNT, $V_{I}$ is the CNT volume fraction, and $[X]$ is given by [18]

$$
\begin{aligned}
{[X]=\frac{1}{2 \pi} \int_{0}^{\pi} d \phi \int_{0}^{\pi} } & {[\Phi]^{-1}\left(\left[C^{M}\right]-\left[C^{I}\right]\right)^{-1}\left[C^{M}\right] } \\
& \times\left(\left(\left[C^{M}\right]-\left[C^{I}\right]\right)^{-1}\left[C^{M}\right]-[S]\right)^{-1} \\
& \times[\Phi] \sin \theta d \theta
\end{aligned}
$$

with $[S]$ being the Eshelby tensor, which is a function of the geometry of CNT and the elastic properties of the matrix, and $[\Phi]$ being given by

$$
[\Phi]=\left[\begin{array}{cccccc}
\cos ^{2} \theta & \sin ^{2} \theta \cos ^{2} \phi & \sin ^{2} \theta \sin ^{2} \phi & \sin ^{2} \theta \sin \phi \cos \phi & \sin \theta \cos \theta \sin \phi & \sin \theta \cos \theta \cos \phi \\
\sin ^{2} \theta & \cos ^{2} \theta \cos ^{2} \phi & \cos ^{2} \theta \sin ^{2} \phi & \cos ^{2} \theta \sin \phi \cos \phi & -\sin \theta \cos \theta \sin \phi & -\sin \theta \cos \theta \cos \phi \\
0 & \sin ^{2} \phi & \cos ^{2} \phi & -\sin \phi \cos \phi & 0 & 0 \\
0 & -2 \cos \theta \sin \phi \cos \phi & 2 \cos \theta \sin \phi \cos \phi & \cos \theta\left(\cos ^{2} \phi-\sin ^{2} \phi\right) & -\sin \theta \cos \phi & \sin \theta \sin \phi \\
0 & -2 \sin \theta \sin \phi \cos \phi & 2 \sin \theta \sin \phi \cos \phi & \sin \theta\left(\cos ^{2} \phi-\sin ^{2} \phi\right) & \cos \theta \cos \phi & -\cos \theta \sin \phi \\
-2 \sin \theta \cos \theta & 2 \sin \theta \cos \theta \cos ^{2} \phi & 2 \sin \theta \cos \phi \sin ^{2} \phi & 2 \sin \theta \cos \theta \sin \phi \cos \phi & \sin \phi\left(\cos ^{2} \theta-\sin ^{2} \theta\right) & \cos \phi\left(\cos ^{2} \theta-\sin ^{2} \theta\right)
\end{array}\right] .
$$

Moreover, the Mori-Tanaka model considering the interaction between CNTs to a certain extent gives

$$
[\bar{C}]=\left[C^{M}\right]+V_{I}\left(\left[C^{I}\right]-\left[C^{M}\right]\right)\left(V_{I}[\mathrm{I}]+\left(1-V_{I}\right)[X]^{-1}\right)^{-1} \text {. }
$$

\section{RESULTS}

In the present work, neat epoxy, 1 wt $\%_{--}, 2 \mathrm{wt} \%-, 3 \mathrm{wt} \%{ }^{-}$, $4 \mathrm{wt} \%-$, and $5 \mathrm{wt} \%$-MWCNT/epoxy composite specimens where MWCNTs exhibit two groups of diameters, D: (i) 
TABLE 1: Tensile strength, Young's modulus, and fracture strain of CNT/epoxy composites.

\begin{tabular}{|c|c|c|}
\hline \multicolumn{3}{|c|}{ Average tensile strength of CNT/epoxy composites (percentage increase) } \\
\hline \multirow{2}{*}{ CNT weight percentage } & \multicolumn{2}{|c|}{ CNT diameter } \\
\hline & $D<20 \mathrm{~nm}(\mathrm{MPa})$ & $D=40 \sim 60 \mathrm{~nm}(\mathrm{MPa})$ \\
\hline 0 (neat epoxy) & \multicolumn{2}{|c|}{$25.67 \pm 0.28$} \\
\hline $1 \mathrm{wt} \%$ & $42.64 \pm 1.47(66.1 \%)$ & $36.63 \pm 1.06(42.7 \%)$ \\
\hline $2 \mathrm{wt} \%$ & $46.03(79.3 \%)$ & $38.97(51.8 \%)$ \\
\hline $3 \mathrm{wt} \%$ & $48.02 \pm 1.46(87.1 \%)$ & $42.52 \pm 1.47(65.6 \%)$ \\
\hline $4 \mathrm{wt} \%$ & $51.10(99.1 \%)$ & $45.78(78.3 \%)$ \\
\hline $5 \mathrm{wt} \%$ & $52.89 \pm 0.79(106 \%)$ & $46.80 \pm 0.51(82.3 \%)$ \\
\hline \multicolumn{3}{|c|}{ Average Young's modulus of CNT/epoxy composites (percentage increase) } \\
\hline \multirow{2}{*}{ CNT weight percentage } & \multicolumn{2}{|c|}{ CNT diameter } \\
\hline & $D<20 \mathrm{~nm}(\mathrm{GPa})$ & $D=40 \sim 60 \mathrm{~nm}(\mathrm{GPa})$ \\
\hline 0 (neat epoxy) & \multicolumn{2}{|c|}{$2.83 \pm 0.22$} \\
\hline $1 \mathrm{wt} \%$ & $3.64 \pm 0.20(28.6 \%)$ & $3.47 \pm 0.15(22.6 \%)$ \\
\hline $2 \mathrm{wt} \%$ & $4.18(47.7 \%)$ & $3.74(32.2 \%)$ \\
\hline $3 \mathrm{wt} \%$ & $4.31 \pm 0.21(52.3 \%)$ & $4.10 \pm 0.17(44.9 \%)$ \\
\hline $4 \mathrm{wt} \%$ & $4.39(55.1 \%)$ & $4.26(50.5 \%)$ \\
\hline $5 \mathrm{wt} \%$ & $4.56 \pm 0.21(61.1 \%)$ & $4.36 \pm 0.20(54.1 \%)$ \\
\hline \multicolumn{3}{|c|}{ Average fracture strain of CNT/epoxy composites (percentage increase) } \\
\hline \multirow{2}{*}{ CNT weight percentage } & \multicolumn{2}{|c|}{ CNT diameter } \\
\hline & $D<20 \mathrm{~nm}$ & $D=40 \sim 60 \mathrm{~nm}$ \\
\hline 0 (neat epoxy) & \multicolumn{2}{|c|}{$0.87 \pm 0.09$} \\
\hline $1 \mathrm{wt} \%$ & $1.19 \pm 0.11(36.8 \%)$ & $1.16 \pm 0.06(33.3 \%)$ \\
\hline $2 w t \%$ & $1.11(27.6 \%)$ & $1.05(20.7 \%)$ \\
\hline $3 w t \%$ & $1.15 \pm 0.01(32.2 \%)$ & $1.05 \pm 0.11(20.7 \%)$ \\
\hline $4 \mathrm{wt} \%$ & $1.20(37.9 \%)$ & $1.08(24.1 \%)$ \\
\hline $5 \mathrm{wt} \%$ & $1.18 \pm 0.11(35.6 \%)$ & $1.10 \pm 0.03(26.4 \%)$ \\
\hline
\end{tabular}

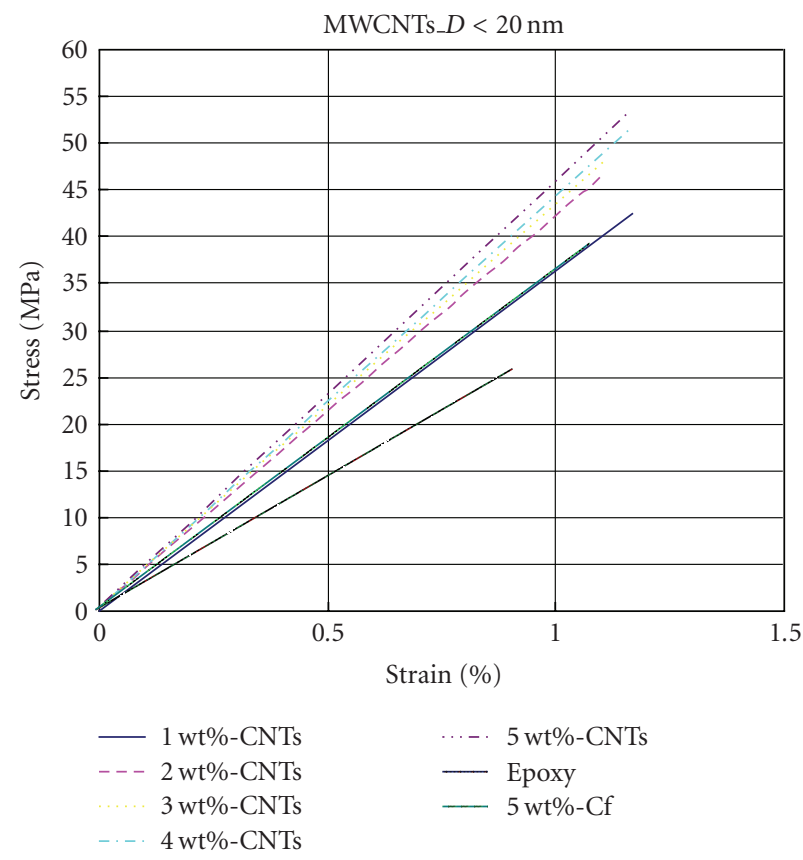

Figure 2: Stress-strain curve of MWCNT/epoxy with CNT diameter $D<20 \mathrm{~nm}$. less than $20 \mathrm{~nm}$ and (ii) between 40 and $60 \mathrm{~nm}$, are used. Typical stress-strain curves of MWCNT/epoxy composites, where CNT diameter $D<20 \mathrm{~nm}$ is shown in Figure 2 while those of MWCNT/epoxy composites with CNT diameter $D$ being $40 \sim 60 \mathrm{~nm}$ could be seen in Figure 3. The composite strength, modulus of elasticity, and fracture strain data are listed in Table 1. The relationship between composite tensile strength and CNT weight fraction is shown in Figure 4 and that between Young's modulus and CNT weight fraction is shown in Figure 5. The experimental results show that the average tensile strength of $1 \mathrm{wt} \%-, 2 \mathrm{wt} \%$-, $3 \mathrm{wt} \%-, 4 \mathrm{wt} \%-$, and $5 \mathrm{wt} \%-\mathrm{MWCNTs} /$ epoxy with a CNT diameter $D<20 \mathrm{~nm}$ increases $66.1 \%, 79.3 \%, 87.1 \%$, $99.1 \%$, and $106.0 \%$, and average Young's modulus increases $28.6 \%, 47.7 \%, 52.3 \%, 55.1 \%$, and $61.1 \%$, respectively. By adding MWCNTs of the same weight fraction with a larger diameter $(D=40 \sim 60 \mathrm{~nm})$, the average tensile strength of $1 \mathrm{wt} \%-, 2 \mathrm{wt} \%-, 3 \mathrm{wt} \%-, 4 \mathrm{wt} \%-$, and $5 \mathrm{wt} \%-$ MWCNTs/epoxy increases 42.7\%, 51.8\%, 65.6\%, 78.3\%, and $82.3 \%$, and average Young's moduli increase $22.6 \%$, $32.2 \%, 44.9 \%, 50.5 \%$, and $54.1 \%$, respectively, compared with average Young's modulus $(2.83 \mathrm{GPa})$ and the average tensile strength $(25.67 \mathrm{MPa})$ of the neat epoxy specimens. Adding MWCNTs into epoxy does increase the mechanical 


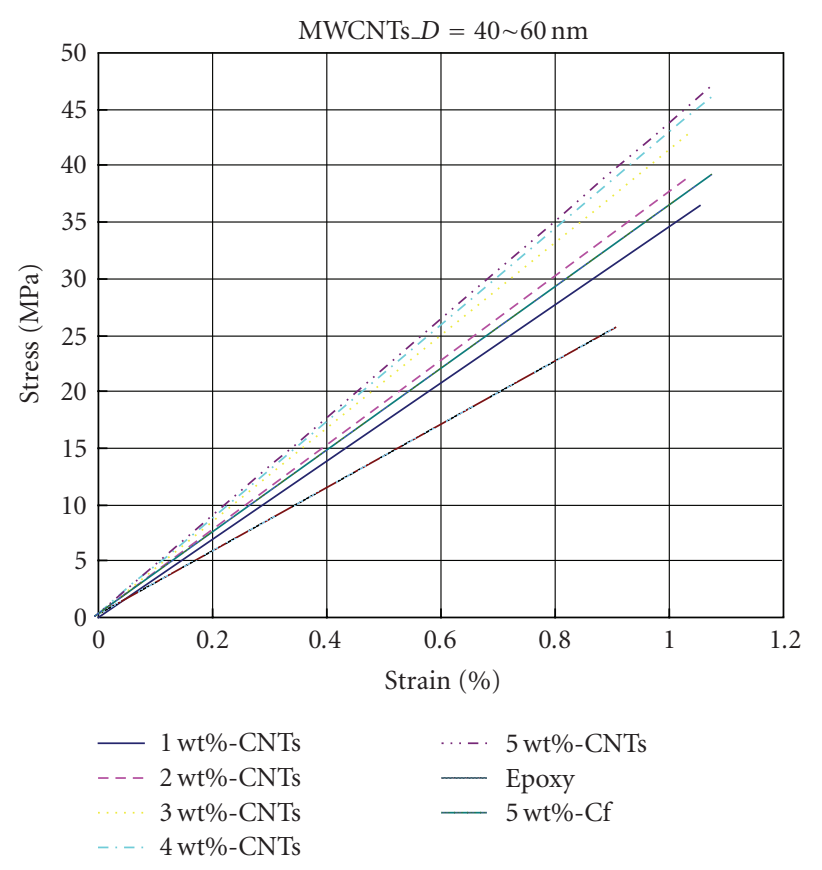

FIgURE 3: Stress-strain curve of MWCNT/epoxy with CNT diameter $D=40 \sim 60 \mathrm{~nm}$.

properties of the composites, and the smaller the CNT diameter is the higher the composite stiffness and strength are.

The fracture surface of a $5 \mathrm{wt} \%$-CNT/epoxy specimen, where the diameter of CNTs is less than $20 \mathrm{~nm}$ is examined using field-emission scanning electron microscopy and is shown in Figure 6. The dispersion of the CNTs is uniform, which contributes to the improved mechanical properties of CNT-based composites [8].

The following elastic properties of a single-crystal graphite sheet (i.e., a graphene) are used in the microstructure-based double-inclusion model developed by $\mathrm{Yu}$ et al. [19] to determine Young's modulus of MWCNT as follows:

$$
[C]=\left[\begin{array}{cccccc}
1060 & 15 & 180 & 0 & 0 & 0 \\
15 & 36.5 & 15 & 0 & 0 & 0 \\
180 & 15 & 1060 & 0 & 0 & 0 \\
0 & 0 & 0 & 4.5 & 0 & 0 \\
0 & 0 & 0 & 0 & 440 & 0 \\
0 & 0 & 0 & 0 & 0 & 4.5
\end{array}\right] \mathrm{GPa}
$$

where the $x_{1}-x_{3}$ plane is the plane of isotropy of a graphene. Poisson's ratios of the graphene are $v_{12}=0.01, v_{23}=0.2$, and $v_{13}=0.2$ [20]. Since two ranges of CNT diameters $(D=40 \sim 60 \mathrm{~nm}$ and $D<20 \mathrm{~nm})$ are used in our specimens, the diameters of two groups of MWCNTs are taken as $50 \mathrm{~nm}$ and $15 \mathrm{~nm}$, respectively, in the present models. The doubleinclusion model [19] gives Young's modulus of an MWCNT with a diameter of $50 \mathrm{~nm}$ as $770 \mathrm{GPa}$, and $1015 \mathrm{GPa}$ for MWCNT with a diameter $15 \mathrm{~nm}$, which is consistent with the available experimental data [21]. Young's modulus of

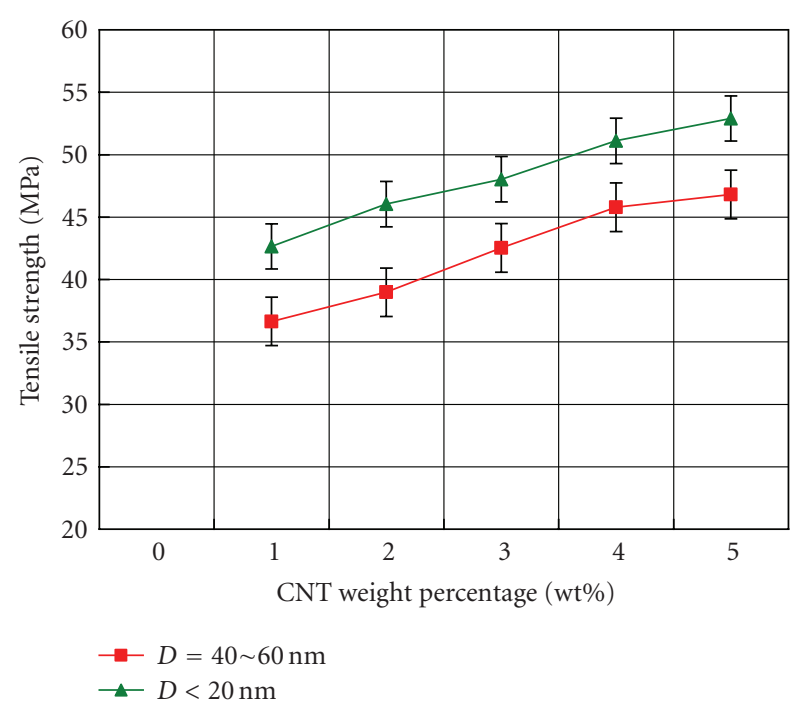

FIGURE 4: Relationship between composites tensile strength and CNT weight percentage.

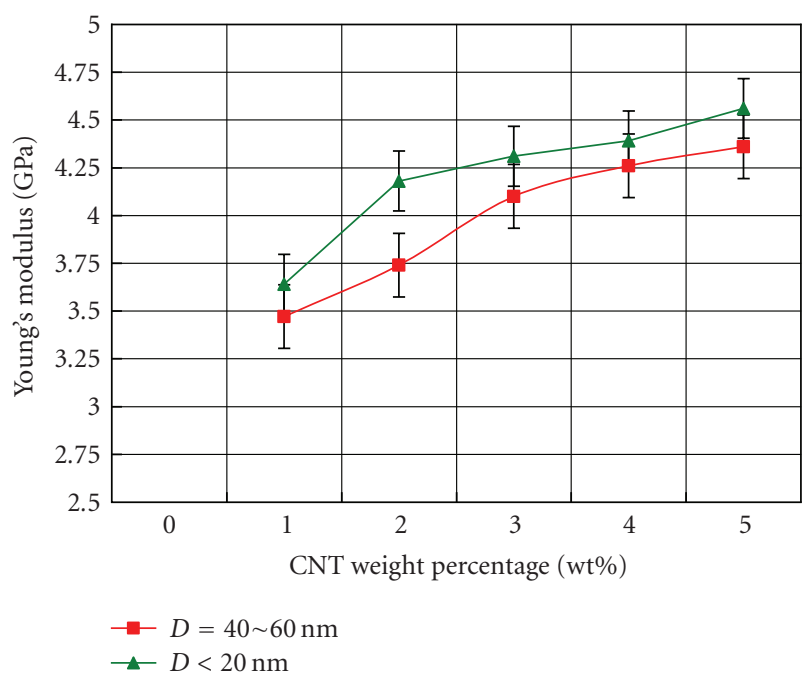

FIGURE 5: Relationship between the composites of Young's modulus and CNT weight percentage.

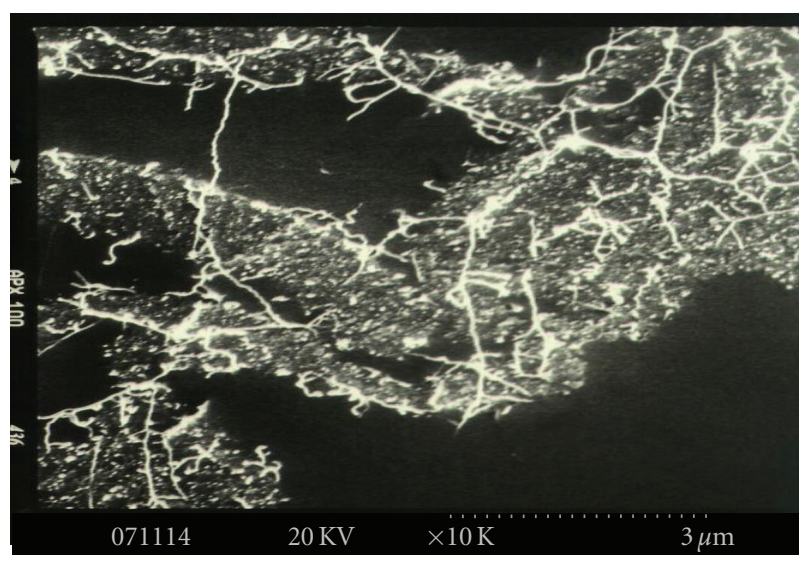

FIGURE 6: The fracture surface of $5 \mathrm{wt} \%$-MWCNT/epoxy specimen $\left(D_{\mathrm{CNT}}<20 \mathrm{~nm}\right)$. 


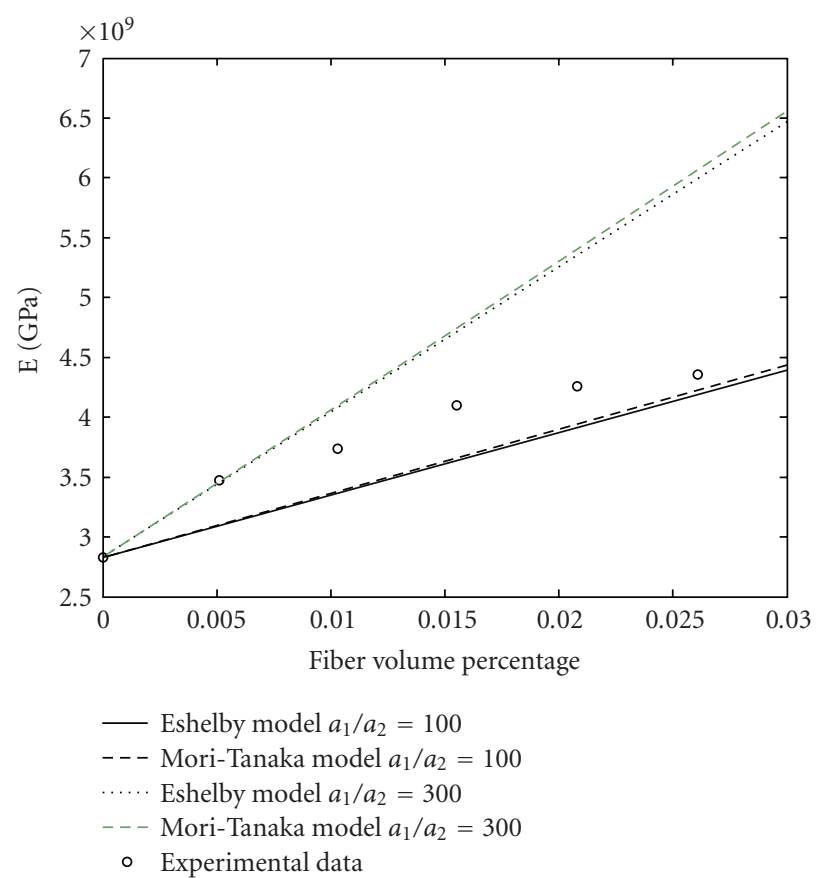

FIgURe 7: Predicted Young's modulus compared with the experimental data of the MWCNT/epoxy composite $D_{\mathrm{CNT}}=40 \sim 60 \mathrm{~nm}$.

epoxy $E_{m}$ is $2.83 \mathrm{GPa}$ and the Poisson's ratio, $v_{f}$, of the CNT is assumed to be 0.2 and that of epoxy, $v_{m}$, is 0.32 . Since the density of MWCNT and that of epoxy are $2.1 \mathrm{~g} / \mathrm{cm}^{3}$ and $1.07 \mathrm{~g} / \mathrm{cm}^{3}$, respectively; the CNT volume fractions are $0.51 \%(1 \mathrm{wt} \%), 1.03 \%$ ( $2 \mathrm{wt} \%$ ), $1.55 \%$ ( $3 \mathrm{wt} \%$ ), $2.08 \%$ ( $4 \mathrm{wt} \%)$, and $2.61 \%(5 \mathrm{wt} \%)$. The lengths of the as received MWCNTs range between 5 and $15 \mu \mathrm{m}$, thus the lower and upper bounds on the aspect ratio $a_{1} / a_{2}$ of MWCNT are roughly estimated as $100 \sim 300$ and $300 \sim 1000$ for the two groups of MWCNTs in our calculations. The predicted values are compared with the experimental data in Figures 7 and 8 for the two groups of CNT diameters $D=40 \sim 60 \mathrm{~nm}$ and $D<20 \mathrm{~nm}$, respectively. The curves in Figures 7 and 8 give the prediction on Young's moduli of the composites reinforced by CNTs with a constant aspect ratio. The experimental data are from specimens reinforced by CNTs with aspect ratios varying in a certain range and, therefore, are not expected to follow the trend of any specific curve in Figures 7 and 8 . However, the experimental data indeed fall within the curves corresponding to the predictions based on the lower and upper bounds on CNT aspect ratio.

\section{CONCLUSION}

In the present work, six groups of specimens-neat epoxy, $1 \mathrm{wt} \%-, \quad 2 \mathrm{wt} \%-, \quad 3 \mathrm{wt} \%-, 4 \mathrm{wt} \%-$, and $5 \mathrm{wt} \%-M W C N T /$ epoxy composites-are prepared and tested. Furthermore, MWCNTs with a diameter $D$ (i) less than $20 \mathrm{~nm}$ and (ii) between 40 and $60 \mathrm{~nm}$ are used in each of the five groups of composites. The tensile test results show that the average tensile strength of $5 \mathrm{wt} \%$-MWCNT/epoxy with a diameter $D<20 \mathrm{~nm}$ increases $106.0 \%$, and average Young's modulus

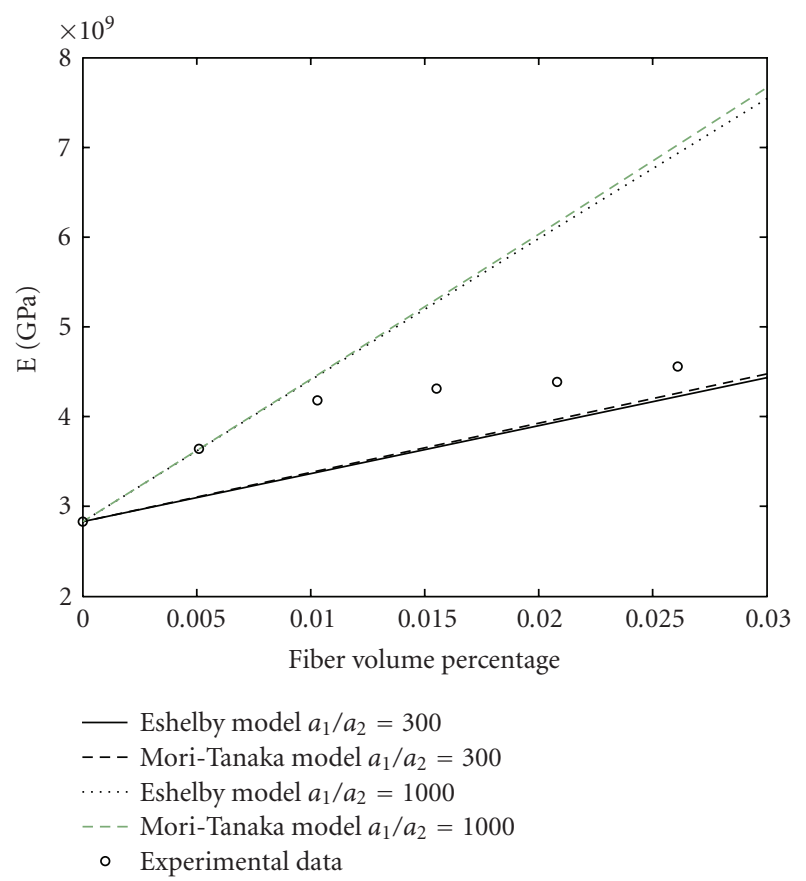

FIgURe 8: Predicted Young's modulus compared with the experimental data of the MWCNT/epoxy composite $D_{\mathrm{CNT}}<20 \mathrm{~nm}$.

increases $61.1 \%$. When the same weight fraction of MWCNT with a larger diameter $D=40 \sim 60 \mathrm{~nm}$ is added into epoxy, the average tensile strength of $5 \mathrm{wt} \%$-MWCNT/epoxy increases $82.3 \%$, and average Young's modulus increases $54.1 \%$, compared with those of neat epoxy, of which the tensile strength is $25.67 \mathrm{MPa}$, and Young's modulus is $2.83 \mathrm{GPa}$. The FESEM observation shows the uniform dispersion of MWCNTs in epoxy resulting in improved mechanical properties of MWCNTs/epoxy composites. Despite the fact that it is not easy to characterize CNT aspect ratio, which are roughly estimated in our models, the experimental data indeed fall within the curves corresponding to the predictions given by Eshelby and Mori-Tanaka models based on the lower and upper bounds on CNT aspect ratio.

\section{ACKNOWLEDGMENT}

This work is supported by the National Science Council in Taiwan under Grant no. NSC95-2221-E-155-016 to Yuan Ze University, Taiwan.

\section{REFERENCES}

[1] R. Andrews, D. Jacques, A. M. Rao, et al., "Nanotube composite carbon fibers," Applied Physics Letters, vol. 75, no. 9, pp. 1329-1331, 1999.

[2] Z. Jia, Z. Wang, C. Xu, et al., "Study on poly(methyl methacrylate)/carbon nanotube composites," Materials Science and Engineering A, vol. 271, no. 1-2, pp. 395-400, 1999.

[3] X. Gong, J. Liu, S. Baskaran, R. D. Voise, and J. S. Young, "Surfactant-assisted processing of carbon nanotube/polymer composites," Chemistry of Materials, vol. 12, no. 4, pp. 10491052, 2000. 
[4] A. Allaoui, S. Bai, H. M. Cheng, and J. B. Bai, "Mechanical and electrical properties of a MWNT/epoxy composite," Composites Science and Technology, vol. 62, no. 15, pp. 19931998, 2002.

[5] K.-T. Lau, S.-Q. Shi, and H. M. Cheng, "Micro-mechanical properties and morphological observation on fracture surfaces of carbon nanotube composites pre-treated at different temperatures," Composites Science and Technology, vol. 63, no. 8, pp. 1161-1164, 2003.

[6] X. Li, H. Gao, W. A. Scrivens, et al., "Nanomechanical characterization of single-walled carbon nanotube reinforced epoxy composites," Nanotechnology, vol. 15, no. 11, pp. 14161423, 2004.

[7] Y. S. Song and J. R. Youn, "Influence of dispersion states of carbon nanotubes on physical properties of epoxy nanocomposites," Carbon, vol. 43, no. 7, pp. 1378-1385, 2005.

[8] E. T. Thostenson and T.-W. Chou, "Aligned multi-walled carbon nanotube-reinforced composites: processing and mechanical characterization," Journal of Physics D, vol. 35, no. 16, pp. L77-L80, 2002.

[9] L. S. Schadler, S. C. Giannaris, and P. M. Ajayan, "Load transfer in carbon nanotube epoxy composites," Applied Physics Letters, vol. 73, no. 26, pp. 3842-3844, 1998.

[10] P. M. Ajayan, L. S. Schadler, C. Giannaris, and A. Rubio, "Single-walled carbon nanotube-polymer composites: strength and weakness," Advanced Materials, vol. 12, no. 10, pp. 750-753, 2000.

[11] C. A. Cooper, R. J. Young, and M. Halsall, "Investigation into the deformation of carbon nanotubes and their composites through the use of Raman spectroscopy," Composites Part A, vol. 32, no. 3-4, pp. 401-411, 2001.

[12] R. Z. Ma, J. Wu, B. Q. Wei, J. Liang, and D. H. Wu, "Processing and properties of carbon nanotubes-nano-SiC ceramic," Journal of Materials Science, vol. 33, no. 21, pp. 5243 5246, 1998.

[13] E. Flahaut, A. Peigney, Ch. Laurent, Ch. Marlière, F. Chastel, and A. Rousset, "Carbon nanotube-metal-oxide nanocomposites: microstructure, electrical conductivity and mechanical properties," Acta Materialia, vol. 48, no. 14, pp. 3803-3812, 2000.

[14] C. L. Xu, B. Q. Wei, R. Z. Ma, J. Liang, X. K. Ma, and D. H. $\mathrm{Wu}$, "Fabrication of aluminum-carbon nanotube composites and their electrical properties," Carbon, vol. 37, no. 5, pp. 855858, 1999.

[15] X. Chen, J. Xia, J. Peng, W. Li, and S. Xie, "Carbonnanotube metalmatrix composites prepared by electroless plating," Composites Science and Technology, vol. 60, no. 2, pp. 301-306, 2000.

[16] J. D. Eshelby, "The determination of the elastic field of an ellipsoidal inclusion, and related problems," Proceedings of the Royal Society of London. Series A, vol. 241, no. 1226, pp. 376396, 1957.

[17] T. Mori and K. Tanaka, "Average stress in matrix and average elastic energy of materials with misfitting inclusions," Acta Metallurgica, vol. 21, no. 5, pp. 571-574, 1973.

[18] Y. W. Chang, Uniaxial stress-strain behavior of MWCNTreinforced epoxy-matrix composites, M.S. thesis, Department of Mechanical Engineering, Yuan Ze University, Chungli, Taiwan, 2005.

[19] N. Yu, Z. H. Zhang, and W. H. Chao, "Analytic estimates on the thermal conductivities and elastic properties of carbon nanotubes," submitted to International Journal of Solids and Structures.
[20] J. Z. Liu, Q. Zheng, and Q. Jiang, "Effect of a rippling mode on resonances of carbon nanotubes," Physical Review Letters, vol. 86, no. 21, pp. 4843-4846, 2001.

[21] E. W. Wong, P. E. Sheehan, and C. M. Lieber, "Nanobeam mechanics: elasticity, strength, and toughness of nanorods and nanotubes," Science, vol. 277, no. 5334, pp. 1971-1975, 1997. 

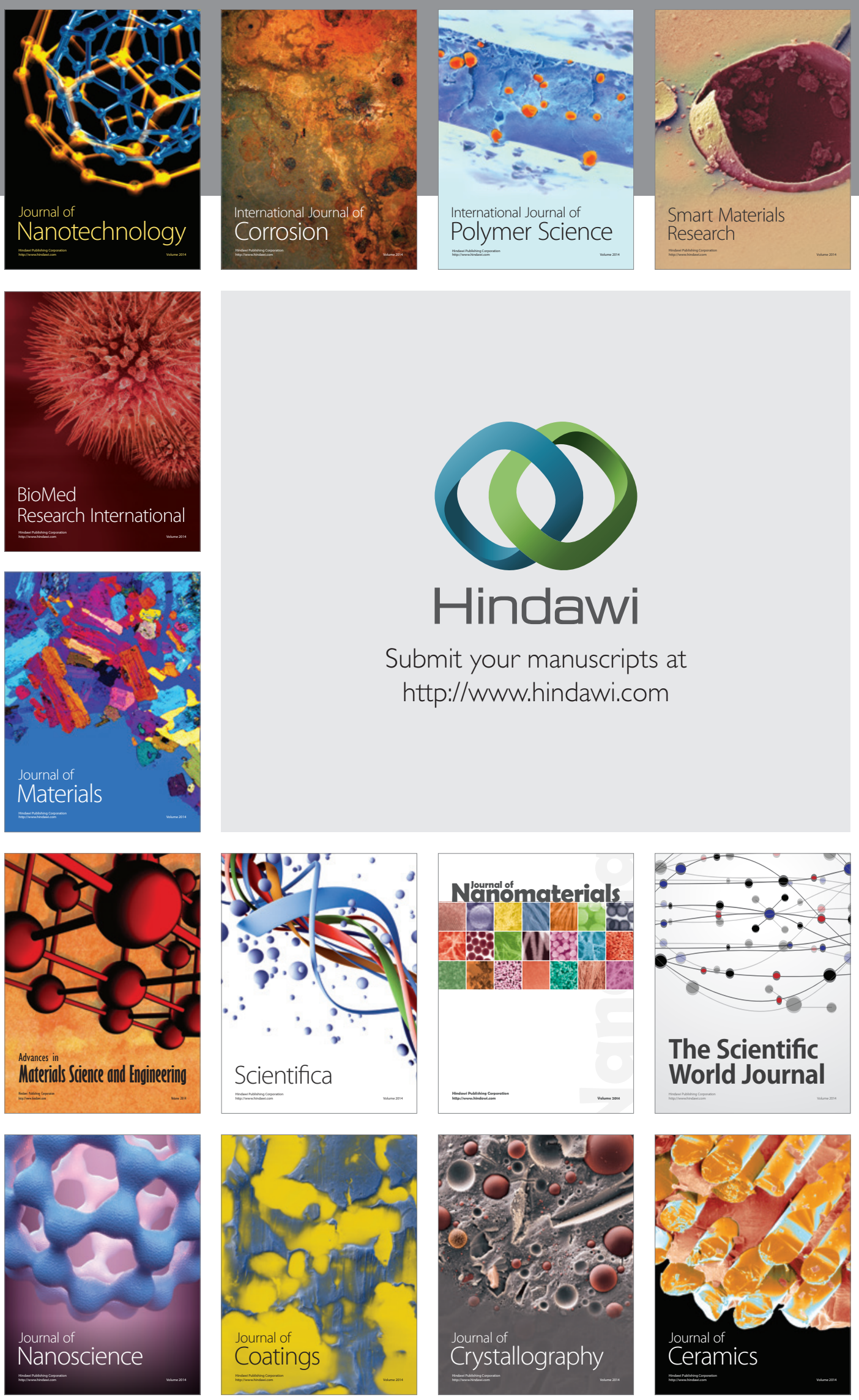

The Scientific World Journal

Submit your manuscripts at

http://www.hindawi.com

\section{World Journal}

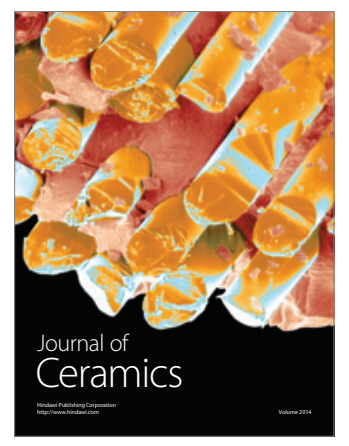

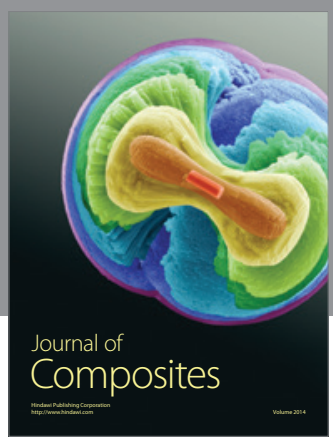
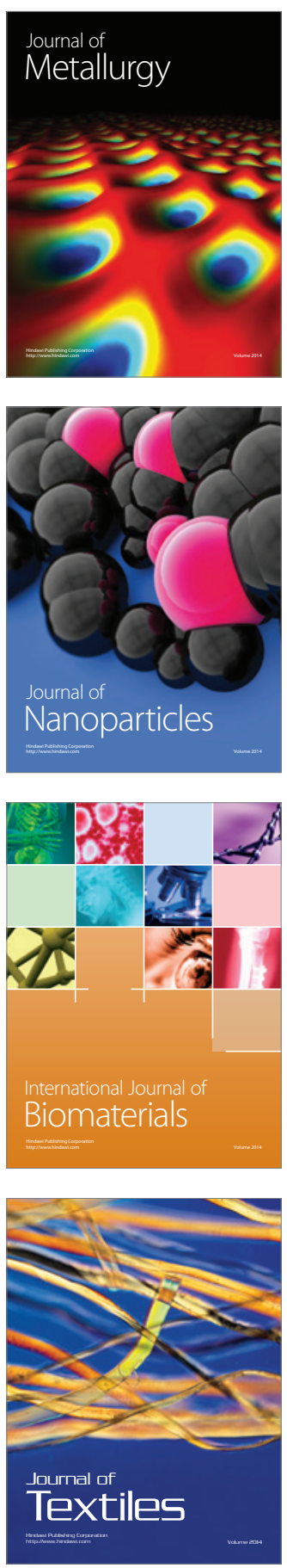